\title{
Analytical constraints on layered gas trapping and smoothing of atmospheric variability in ice under low-accumulation conditions
}

\author{
Kévin Fourteau ${ }^{1}$, Xavier Faïn ${ }^{1}$, Patricia Martinerie ${ }^{1}$, Amaëlle Landais ${ }^{2}$, Alexey A. Ekaykin ${ }^{3}$, Vladimir Ya. Lipenkov ${ }^{3}$, \\ and Jérôme Chappellaz ${ }^{1}$ \\ ${ }^{1}$ Univ. Grenoble Alpes, CNRS, IRD, Grenoble INP, IGE, 38000 Grenoble, France \\ ${ }^{2}$ Laboratoire des Sciences du Climat et de l'Environnement, UMR8212, CEA-CNRS-UVSQ-UPS/IPSL, \\ Gif-sur-Yvette, France \\ ${ }^{3}$ Climate and Environmental Research Laboratory, Arctic and Antarctic Research Institute, \\ St. Petersburg, 199397, Russia
}

Correspondence: Kévin Fourteau (kevin.fourteau@univ-grenoble-alpes.fr) and Patricia Martinerie (patricia.martinerie@univ-grenoble-alpes.fr)

Received: 6 June 2017 - Discussion started: 4 July 2017

Revised: 16 November 2017 - Accepted: 17 November 2017 - Published: 13 December 2017

\begin{abstract}
We investigate for the first time the loss and alteration of past atmospheric information from air trapping mechanisms under low-accumulation conditions through continuous $\mathrm{CH}_{4}$ (and $\mathrm{CO}$ ) measurements. Methane concentration changes were measured over the DansgaardOeschger event 17 (DO-17, $~ 60000 \mathrm{yr} \mathrm{BP}$ ) in the Antarctic Vostok 4G-2 ice core. Measurements were performed using continuous-flow analysis combined with laser spectroscopy. The results highlight many anomalous layers at the centimeter scale that are unevenly distributed along the ice core. The anomalous methane mixing ratios differ from those in the immediate surrounding layers by up to $50 \mathrm{ppbv}$. This phenomenon can be theoretically reproduced by a simple layered trapping model, creating very localized gas age scale inversions. We propose a method for cleaning the record of anomalous values that aims at minimizing the bias in the overall signal. Once the layered-trapping-induced anomalies are removed from the record, DO-17 appears to be smoother than its equivalent record from the high-accumulation WAIS Divide ice core. This is expected due to the slower sinking and densification speeds of firn layers at lower accumulation. However, the degree of smoothing appears surprisingly similar between modern and DO-17 conditions at Vostok. This suggests that glacial records of trace gases from low-accumulation sites in the East Antarctic plateau can provide a better time resolution of past atmospheric composition changes than previously expected. We also developed a
\end{abstract}

numerical method to extract the gas age distributions in ice layers after the removal of the anomalous layers based on comparison with a weakly smoothed record. It is particularly adapted for the conditions of the East Antarctic plateau, as it helps to characterize smoothing for a large range of very low-temperature and low-accumulation conditions.

\section{Introduction}

In a context of climate change, the study of paleoclimate is an important tool for understanding the interactions between climate and atmospheric conditions (Masson-Delmotte et al., 2013). Ice cores have been used to retrieve climatic and atmospheric conditions back to 800000 years before present (BP) (Jouzel et al., 2007; Loulergue et al., 2008; Lüthi et al., 2008). Notably, ancient atmospheric gases get enclosed within bubbles in the ice and allow us to reconstruct the past history of atmospheric composition (Stauffer et al., 1985). The trapping of air in ice is due to the transformation of firn (porous compacted snow) into airtight ice at depths ranging from $\sim 50$ to $\sim 120 \mathrm{~m}$ depending on temperature and accumulation conditions. It is characterized by an increase in bulk density and a decrease in porosity with depth along the firn column. It is only at the bottom of the firn column that the porosity of the medium gets closed and traps the interstitial air. From a gas point of view the firn is traditionally divided 
in three main parts from the surface to the bottom: the convective zone, the diffusive zone, and the trapping zone (e.g., Schwander, 1989; Buizert et al., 2012). The convective zone is characterized by the mixing of air in the snow with atmospheric air through wind action (Colbeck, 1989). In the diffusive zone the dominant gas transport processes are molecular diffusion and gravitational settling. Finally, the trapping zone corresponds to the enclosure of air into bubbles through the closure of the porosity. The process of densification and pore closure can last for thousands of years at the most arid sites in Antarctica.

Air trapping affects the recording of atmospheric variability in ice cores. One known effect of the gas enclosure mechanism is the damping of fast variations in the atmosphere, also called smoothing (Spahni et al., 2003; Joos and Spahni, 2008; Köhler et al., 2011; Ahn et al., 2014). This smoothing arises for two reasons: (i) the gas diffusion in the firn mixes air from different dates, and thus a bubble does not enclose gases with a single age but rather an age range (Schwander et al., 1993; Rommelaere et al., 1997; Trudinger et al., 1997; Witrant et al., 2012); (ii) in a given horizontal layer, bubble enclosure takes place over a range of time rather than instantaneously. These two phenomena combined mean that at a given depth, the air enclosed is represented by a gas age distribution and not by a single age (Schwander et al., 1993; Rommelaere et al., 1997). Gas enclosure mechanisms thus act as a low-pass filter, attenuating signals whose periods are too short compared to the span of the distribution. Spahni et al. (2003) reported the only existing observations of the smoothing effect under low-accumulation conditions. They concluded that the abrupt methane variation during the cold event of $8.2 \mathrm{kyr}$ BP recorded in the EPICA Dome C ice core, compared with its counterpart from the Greenland GRIP ice core, had experienced an attenuation of 34 to $59 \%$. Sites with low accumulation tend to have broader age distributions leading to a stronger damping effect (Spahni et al., 2003; Joos and Spahni, 2008; Köhler et al., 2011; Ahn et al., 2014). A heuristic explanation is that the span of the age distribution is directly related to the densification speed of a firn layer, which is slow at the low-temperature and arid sites of the Antarctic plateau. For the most arid sites the impact of diffusive mixing is negligible compared to progressive trapping, and the smoothing is hence mainly driven by the speed of porosity closure.

Even if the bulk behavior in firn is the increase in density and decrease in open porosity with depth, local physical heterogeneities affect firn densification and gas trapping (Stauffer et al., 1985; Martinerie et al., 1992; Hörhold et al., 2011; Fujita et al., 2016). Working on ice cores and firn from highaccumulation sites, Etheridge et al. (1992), Mitchell et al. (2015), and Rhodes et al. (2016) have discussed the influence of centimeter-scale physical variability in firn on recorded gas concentrations. They argue that physical heterogeneities can lead to variations in closure depth for juxtaposed ice layers. For instance, a given layer could reach bubble enclo- sure at a shallower depth and earlier (respectively deeper and later) than the surrounding layers in the firn, thus trapping relatively older gases (respectively younger gases). In periods of atmospheric variations in trace gas composition occurring on a similar timescale as the trapping process, this mechanism can lead to gas concentration anomalies along depth in an ice core and has been called layered bubble trapping. Based on observations in high-accumulation Greenland ice cores and modeling for the WAIS Divide ice core, Rhodes et al. (2016) report that such artifacts can reach $40 \mathrm{ppbv}$ in the methane $\left(\mathrm{CH}_{4}\right)$ record during the industrial time. In addition, the amplitude of the artifacts increases with lower accumulation rates.

Here we investigate for the first time the existence and impacts of heterogeneous trapping and smoothing in very low-accumulation conditions using continuous measurements of trace gases. High-resolution methane concentration (combined with carbon monoxide) measurements were performed along a section of the Vostok 4G-2 ice core drilled in the Antarctic plateau. The section studied corresponds to the Dansgaard-Oeschger event number 17 (DO$17, \sim 60000 \mathrm{yr}$ BP), a climatic event associated with particularly fast and large atmospheric methane variations (Brook et al., 1996; Chappellaz et al., 2013; Rhodes et al., 2015). This makes this event especially adapted for the quantification of both gas record smoothing and layered trapping. To interpret our data we compare them with the much less smoothed methane record measured in the WAIS Divide ice core (WDC, Rhodes et al., 2015), where the accumulation rate is an order of magnitude larger than at Vostok.

\section{Ice core samples and analytical methods}

\subsection{Vostok ice samples}

The ice core analyzed in this study is the 4G-2 core drilled at Vostok, East Antarctica in the 1980s (Vasiliev et al., 2007). Measured depths range from 895 to $931 \mathrm{~m}$, with a cumulative length of $27.5 \mathrm{~m}$ due to several missing portions in the archived ice at Vostok station. The ice core sections analyzed have been stored at Vostok station since the drilling and were transported to the Institut des Geosiences de l'Environnement (IGE, Grenoble, France; formerly LGGE) 3 months before analyses. Although stored at Vostok at temperatures of $\sim-50^{\circ} \mathrm{C}$, the samples showed clathrate relaxation cavities. The gas age over this depth interval spans a 3000 -year interval centered on $59400 \pm 1700 \mathrm{yrBP}$ (Bazin et al., 2013; Veres et al., 2013). The estimated snow accumulation rate at the Vostok core site for this period is $1.3 \pm 0.1 \mathrm{cmice} \mathrm{yr}^{-1}$ (Bazin et al., 2013; Veres et al., 2013). Even though DO events are associated with large warmings in the Northern Hemisphere, isotopic records indicate that DO-17 temperatures on the Antarctic plateau remain at least $5^{\circ} \mathrm{C}$ below modern temperatures (Fig. 2 in Jouzel et al., 2007). 


\subsection{Continuous methane measurements}

The Vostok 4G-2 ice core sections were analyzed at high resolution for methane concentration (and carbon monoxide as a by-product) at IGE over a 5-day period and using a continuous ice core melting system with online gas measurements (CFA, continuous-flow analysis). Detailed descriptions of this method have been reported before (Stowasser et al., 2012; Chappellaz et al., 2013; Rhodes et al., 2013). Ice core sticks of 34 by $34 \mathrm{~mm}$ were melted at IGE at a mean rate of $3.8 \mathrm{~cm} \mathrm{~min}^{-1}$ using a melt head as described by Bigler et al. (2011), and the water and gas bubble mixture was pumped toward a low-volume T-shaped glass debubbler. All the gas bubbles and approximately $15 \%$ of the water flow were transferred from the debubbler to a gas extraction unit maintained at $30^{\circ} \mathrm{C}$. The gas was extracted by applying a pressure gradient across a gas-permeable membrane (optimized IDEX in-line degasser; internal volume $1 \mathrm{~mL}$ ). The gas pressure recorded downstream of the IDEX degasser was typically $500-600$ mbar and was sufficiently low to extract all visible air bubbles from the sample mixture. A homemade Nafion dryer with a $30 \mathrm{~mL} \mathrm{~min}^{-1}$ purge flow of ultrapure nitrogen (Air Liquide; $99.9995 \%$ purity) dried the humid gas sample before entry into the laser spectrometer. Online gas measurements of methane were conducted with a SARA laser spectrometer developed at Laboratoire Interdisciplinaire de Physique (Grenoble, France) based on optical-feedback cavity-enhanced absorption spectroscopy (OF-CEAS; Morville et al., 2005; Romanini et al., 2006). Such a laser spectrometer has been used before for continuous-flow gas analyses (e.g., Chappellaz et al., 2013; Rhodes et al., 2013, 2015, 2016; Faïn et al., 2014); however, the IGE CFA system was specifically optimized to reduce experimental smoothing by limiting all possible dead and mixing volumes along the sample line. For this study the rate of OF-CEAS spectrum acquisition was $6 \mathrm{~Hz}$. The $12 \mathrm{~cm}^{3}$ optical cavity of the spectrometer was maintained at $30 \mathrm{mbar}$ of internal pressure, which corresponds to an equivalent cavity volume of only $0.36 \mathrm{~cm}^{3}$ at STP and allows for a fast transit time of the gaseous sample in the cavity. Consequently, the SARA instrument introduces a significantly lower smoothing than the CFA setup. The SARA spectrometer was carefully calibrated onto the NOAA2004 scale (Dlugokencky et al., 2005) before the CFA analyses using three synthetic air standards with known methane concentrations (Scott-Marrin, Inc.; Table $\mathrm{S} 1$ in the Supplement). $\mathrm{CH}_{4}$ concentrations measured during the calibration agreed with NOAA measurements within $0.1 \%$ over a $360-1790$ ppbv range. A linear calibration law was derived and applied to all $\mathrm{CH}_{4}$ data (Fig. S1 in the Supplement).

Allan variance tests (Allan, 1966; Rhodes et al., 2013) were conducted using mixtures of degassed deionized water and synthetic air standard to evaluate both the stability and the precision of the measurements. The best Allan variance was obtained with an integration time larger than $1000 \mathrm{~s}$, illustrating the very good stability of the CFA system. However, in order to optimize the depth resolution of our measurements, we used an integration time of $1 \mathrm{~s}$ for which a precision of $2.4 \mathrm{ppbv}(1 \sigma)$ was observed. This corresponds to a peak-to-peak $\mathrm{CH}_{4}$ variability of $\sim 10 \mathrm{ppbv}$. Hereafter, this variability will be referred to as analytical noise.

The mixing of gases and meltwater during the sample transfer from the melt head to the laser spectrometer induces a CFA experimental smoothing of the signal. The extent of the CFA-based damping was determined by performing a step test (left panel of Fig. S2), i.e., a switch between two synthetic mixtures of degassed DI water and synthetic air standards of different methane concentrations, following the method of Stowasser et al. (2012). It shows that the CFA system can resolve signals down to the centimeter scale. We were also able to extract the impulse response of the system that will be used in Sect. 4.3 to emulate CFA smoothing. A more detailed discussion of the frequency response of the system can be found in Sect. S2. Breaks along the core regularly let ambient air enter the system, resulting in strong positive spikes in methane concentration. In order to remove these contamination artifacts, exact times corresponding to a break running through the melt head were recorded during the measurements and later used to identify and clean the data from contamination.

\subsection{Nitrogen isotopes}

The ratio of stable nitrogen isotopes, ${ }^{15} \mathrm{~N} /{ }^{14} \mathrm{~N}$, was measured at the Laboratoire des Sciences du Climat et de l'Environnement (LSCE), France. Briefly, a melting technique followed by gas condensation in successive cold traps was used to extract the air from the ice, and the air samples were then transferred to a dual-inlet mass spectrometer (Delta V Plus; Thermo Scientific). The analytical method and corrections applied to the results are described in Landais et al. (2004) and the references therein.

The results are expressed as deviations from the nitrogen isotopic ratio in dry atmospheric air $\left(\delta^{15} \mathrm{~N}\right)$. Discrete samples every $50 \mathrm{~cm}$ and duplicates were analyzed when possible. A total of 96 data points, including 39 duplicates were obtained. The pooled standard deviation over duplicate samples is $0.011 \%$.

\section{Experimental results}

\subsection{Methane record}

The methane record spanning the DO-17 event extracted from the Vostok 4G-2 ice core is presented in blue in Fig. 1. Two corrections were applied to these data: (i) data screening and removal of kerosene contamination and (ii) full dataset calibration to account for the preferential dissolution of methane during the melting process. 
Kerosene, used as drilling fluid for the Vostok 4G-2 ice core extraction, was detected in some of the meltwater from our continuous-flow analysis. This contamination induces surface iridescent colors and a strong characteristic smell; it was detected not only in the meltwater from the outer part of our ice sticks but also in some of the meltwater from the center of the ice samples. However, the continuous flow of the meltwater does not allow us to clearly identify the contaminated ice core sections. Carbon monoxide (CO) was measured simultaneously with methane by using our laser spectrometer (Faïn et al., 2014). We attributed simultaneous anomalies in $\mathrm{CH}_{4}$ (increase of about $20 \mathrm{ppbv}$ or more) and $\mathrm{CO}$ (increase of about $100 \mathrm{ppbv}$ or more) mixing ratios to kerosene contamination and suppressed the corresponding data by visual inspection of the dataset. An example of such a kerosene contamination is visible in Fig. S3. Chappellaz et al. (1990) indicate that methane contamination lower than 40 ppbv was observed by discrete measurements in the brittle zone of the Vostok 3G core, which is consistent with our observation in 4G-2. The impact of kerosene contamination on $\mathrm{CO}$ in ice cores has not been quantified so far. Adding the length of all kerosene-affected ice core sections, a total of $2.1 \mathrm{~m}$ of data was removed. The calibration of the methane mixing ratio for preferential solubility (Rhodes et al., 2013) was achieved by matching our continuous methane measurements with the already calibrated WDC methane dataset (Rhodes et al., 2015), as described in Sect. S1.2. The resulting methane record has a high resolution, but presents numerous discontinuities due to missing ice, ambient air infiltration, and kerosene contamination. The signal displays two distinct scales of variability.

Atmospheric-history-relevant variability. The general shape of the signal can be divided in two parts, a stable zone extending from 931 to $915 \mathrm{~m}$ of depth and two consecutive methane variations of approximately $100 \mathrm{ppbv}$ each, extending respectively from 915 to $907 \mathrm{~m}$ and from 907 to $895 \mathrm{~m}$. They respectively correspond to the plateau preceding the DO-17 event and the DO-17 event itself.

Centimeter-scale variability. The signal also displays centimeter-scale methane variations. A portion of these variations is explained by the $10 \mathrm{ppbv}$ analytical noise of the CFA system. However, in the upper part of the core (above $915 \mathrm{~m}$ ) the signal also exhibits abrupt variations with amplitudes reaching up to $50 \mathrm{ppbv}$ and widths of about $2 \mathrm{~cm}$. Most of those spikes are negatively orientated and therefore laboratory air or kerosene contamination can be ruled out. It should be noted that the width of the spikes is in the attenuation range of the CFA system, meaning that the true signal in the core has a somewhat larger amplitude than the measured signal. Moreover, the spikes exhibit a specific distribution with depth. For instance, no spike is observed in the lower part of the ice core where the methane concentration is essentially flat, and only negative spikes appear between 900 and $905 \mathrm{~m}$ of depth as seen in the zoomed part of Fig. 1.

\subsection{Revised age scale using Nitrogen isotopes}

The current reference chronology for the Vostok ice core is the Antarctic Ice Core Chronology 2012 (AICC2012; Bazin et al., 2013; Veres et al., 2013). However, only two gas stratigraphic links between Vostok and other cores are available for the DO-17 period in AICC2012, leading to relatively large uncertainties in the Vostok gas age scale over this period. The $\delta^{15} \mathrm{~N}$ of $\mathrm{N}_{2}$ profile over the DO-17 event in the Vostok core is shown Fig. 1. We fitted the experimental values with a linear regression (slope of $9.63 \times 10^{-4} \% \mathrm{om}^{-1}$ and intercept of $-0.417 \%$ o). Considering the diffusive zone of the firn to be stratified according to a barometric equilibrium (Craig et al., 1988; Orsi et al., 2014), its height can be expressed as $H=(R T / g \Delta M) \ln \left(1+\delta^{15} \mathrm{~N}\right)$, where $R$ is the ideal gas constant, $T$ the temperature, $g$ the gravitational acceleration, and $\Delta M$ the difference in molar mass between ${ }^{14} \mathrm{~N}$ and ${ }^{15} \mathrm{~N}$. With a firn temperature of $217 \mathrm{~K}$ (Petit et al., 1999), the mean $\delta^{15} \mathrm{~N}$ value of $0.46 \%$ translates into a diffusive column height of $85 \mathrm{~m}$ and an LIDIE (lock-in depth in ice equivalent) of $59 \mathrm{~m}$ (using a mean firn relative density of $D=0.7$ ). This value lies in the lower range of the AICC2012 LIDIE estimations for this depth range in the Vostok ice core: 58 to $70 \mathrm{~m}$ (Bazin et al., 2013; Veres et al., 2013).

The age difference between the ice and the enclosed gases ( $\triangle$ Age) can be estimated using the height of the firn with $\Delta$ Age $=\left(H+H_{\text {conv }}\right) D /$ accu, where $H$ and $H_{\text {conv }}$ are the heights of the diffusive and convective zones, respectively, $D$ is the average density of the firn column, and "accu" the accumulation rate. Present-day observations report a convective zone spanning down to $13 \mathrm{~m}$ at Vostok (Bender et al., 1994). We used this value as an estimate for the convective zone depth during DO-17. In Fig. 2, the $\Delta$ Age values inferred from our $\delta^{15} \mathrm{~N}$ record using $D=0.7$ and an accumu-

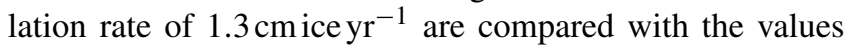
from AICC2012 (Bazin et al., 2013; Veres et al., 2013). The AICC2012 $\Delta$ Age values display a variability of several centuries as shown by the dashed black line in Fig. 2. These variations are sufficient to induce significant distortions in the duration of methane events. These distortions affect the comparison between our measurements and the WDC record from Rhodes et al. (2015), as seen in Fig. S11. Furthermore, the amplitude of the $\Delta$ Age variations is similar to the uncertainty in gas age (1479 to 1841 years). The studied period is fairly stable in terms of temperature and accumulation at Vostok (Petit et al., 1999; Bazin et al., 2013; Veres et al., 2013); thus the $\triangle$ Age changes in the AICC2012 chronology are likely to result from artifacts of the optimization method rather than to correspond with actual variations. We hence revised the AICC2012 gas age scale by deriving a new smooth gas age using the AICC2012 ice age scale and our $\Delta$ Age values inferred from the linear interpolation of $\delta^{15} \mathrm{~N}$ data (Fig. 2). This new smooth chronology enables us to visually identify the different subparts of the DO-17 event between the Vostok and WDC methane records. It is important 


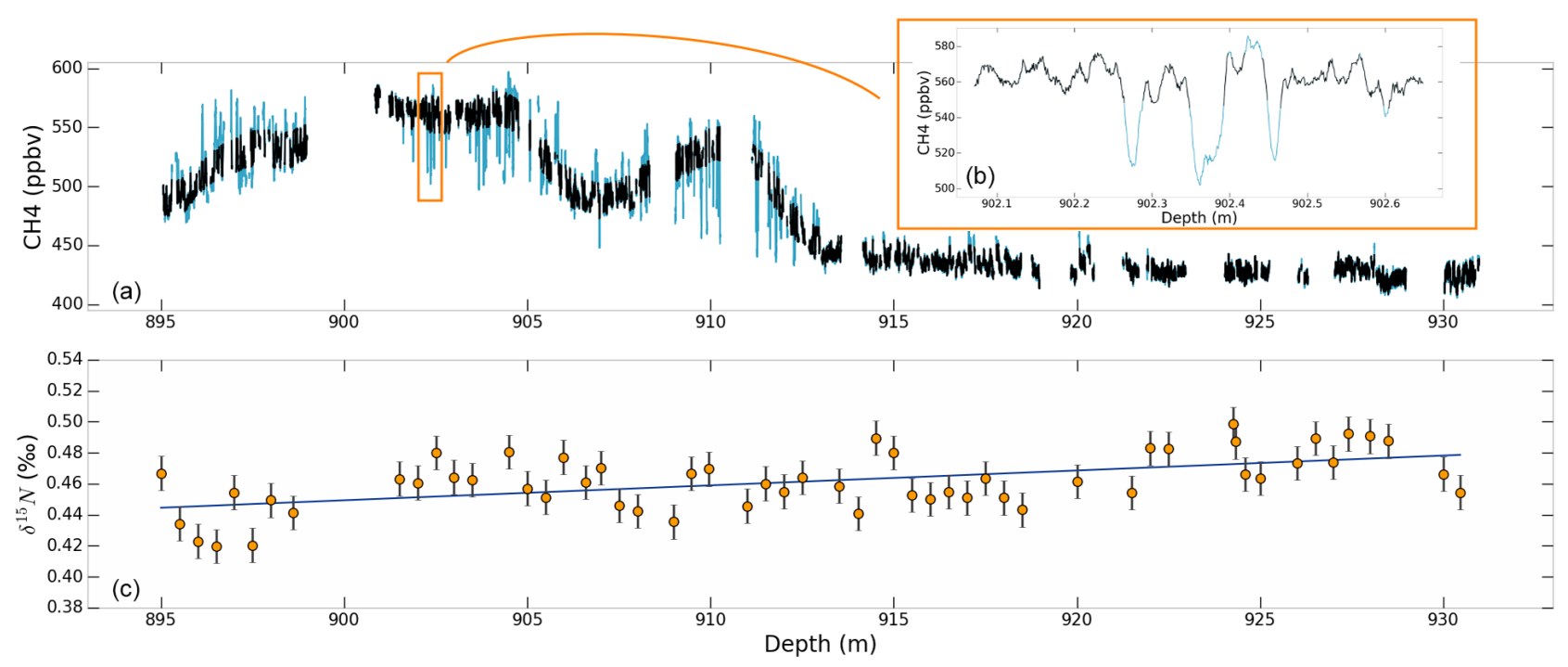

Figure 1. (a) Methane concentration along the Vostok 4G-2 ice core. In blue: data cleaned from ambient air and kerosene contamination and calibrated. In black: data cleaned from layered trapping. (b) Zoom of the section from 902.0 to $902.7 \mathrm{~m}$; (c) $\delta^{15} \mathrm{~N}$ of $\mathrm{N}_{2}$ as a function of depth in the Vostok 4G-2 ice core. Orange dots: isotopic measurements. The vertical error bars correspond to the pooled standard deviation. In blue: linear regression.

to note that this gas age chronology will again be improved by matching the Vostok and WDC methane records (see Sect. 5.2). The corresponding $\Delta$ Age of this final chronology is displayed as the green line in Fig. 2.

\section{Layered bubble trapping}

\subsection{Conceptual considerations of the layered trapping mechanism}

Due to heterogeneities in firn density and porosity, an ice layer may undergo early gas trapping (Etheridge et al., 1992; Rhodes et al., 2013; Mitchell et al., 2015; Rhodes et al., 2016). Thus during gas trapping, the corresponding layer is at a more advanced state of closure than the surrounding bulk layers. Similarly, some layers may undergo a late closure. If gases can circulate through the open porosity surrounding the anomalous layers, the early closed layers will contain abnormally ancient gas with respect to the surrounding layers. On the other hand, layers closed late will contain abnormally recent gas. This leads to very local inversions of the gas age scale along depth. As explained in Rhodes et al. (2016), such a mechanism affects trace gas records only during periods of variations in the concentration of atmospheric gases. Then, abnormal layers contain air significantly different in composition from surrounding layers and appear as spikes in the record. On the other hand, during periods without atmospheric variations, the abnormal layers do not contain air significantly different in composition from their surroundings, and the gas record is not affected.

The orientation of layered trapping spikes depends on the type of atmospheric variations, as illustrated in Fig. 3. For instance, in a period of local maximum in methane concentrations, both early and late closures tend to enclose air with lower mixing ratios, as displayed in case A in Fig. 3. Similarly, in periods of methane minima, abnormal layers tend to enclose air with larger mixing ratios, as displayed in case C in Fig. 3. In the case of monotonous increase or decrease, early and late closures lead to artifacts with opposite signs, as represented by case B in Fig. 3. It should be noted that early and late closures are not expected to affect the record with the same importance. Indeed, a late pore closure means that the surrounding firn is sealed and prevents long-distance gas transport. The latest closure layers will not be able to trap young air if gas transport is impossible in the surrounding firn layers, resulting in less important artifacts.

\subsection{Observed layered trapping in the Vostok 4G-2 ice core}

The positive and negative spikes observed in the Vostok 4G2 methane record introduced in Sect. 3.1 are consistent with the expected impacts of layered trapping. First, the absence of spikes in the lower part of the record below $915 \mathrm{~m}$ is consistent with the absence of an overall methane trend over the corresponding period. Moreover, in periods of methane local maxima at around 903 and $910 \mathrm{~m}$ of depth, most of the spikes are negatively oriented as expected with the conceptual mechanism of layered bubble trapping (cf. case A in Fig. 3).

Thin sections of ice covering the depth range between 902.0 and $902.42 \mathrm{~m}$ (zoomed range in Fig. 1) have been analyzed to investigate whether structural anomalies were 


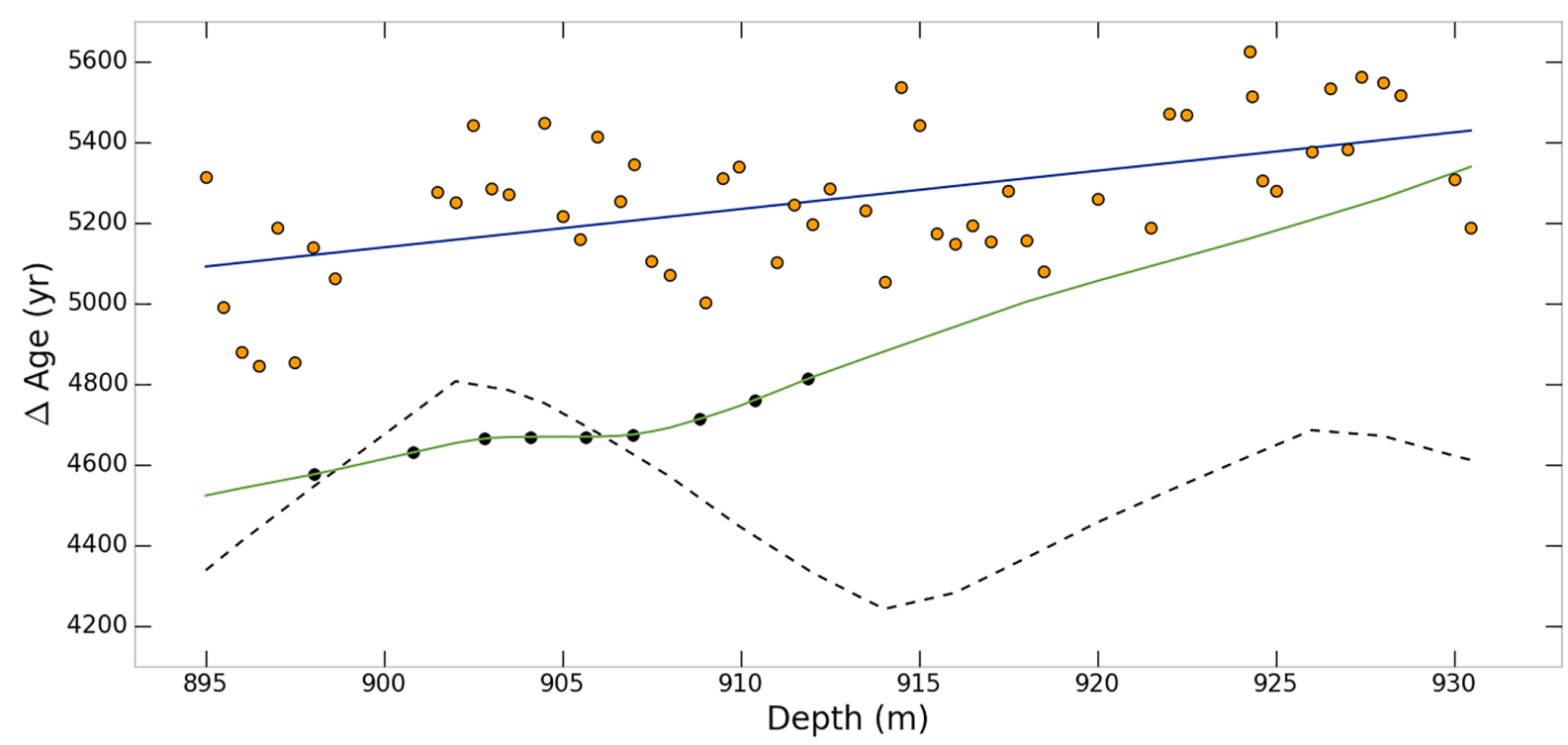

Figure 2. $\Delta$ Age along the Vostok record. Orange dots: $\Delta$ Age directly estimated from $\delta^{15} \mathrm{~N}$ measurements. In blue: $\Delta$ Age derived from the linear regression on isotopic measurements. Black dashed line: $\triangle \mathrm{Age}$ as given by AICC2012. In green: $\Delta$ Age after matching with the WDC $\mathrm{CH}_{4}$ record. Black dots: tie points (minima, maxima, and mid-slope points) used to match the WDC record (see Sect. 5.2).

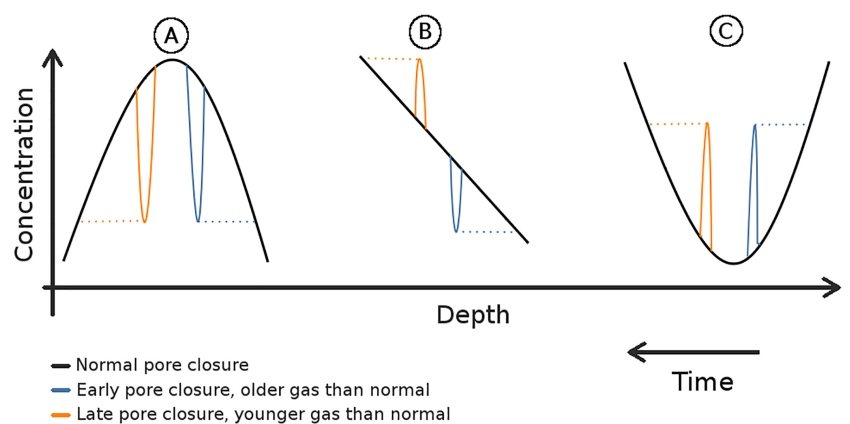

Figure 3. Expected orientation of layered trapping artifacts depending on the characteristics of atmospheric variations. Black curves correspond to a normal chronological trapping, blue to early pore closure, and orange to late pore closure. Cases $\mathrm{A}, \mathrm{B}$, and $\mathrm{C}$ respectively represent local maximum, monotonous trend, and local minimum situations.

associated with anomalous trapping. The method is described in detail in Sect. S4. We were not able to observe any link between the grain sizes and abnormal layers in the methane record. Nonetheless, structural anomalies may have existed at the time of pore closure before disappearing with $\sim 60000$ years of grain evolution. Explanations for the methane anomalies other than layered trapping were considered as well. Looking for a correlation between ice quality and methane anomalies was also a motivation for the above thin section analysis. Although the samples showed small clathrate relaxation cavities, the CFA sticks did not reveal visual signs of stratification possibly associated with abnormal layers. Examples of a CFA stick picture and thin section results are provided in the Supplement. The ice samples were not large enough to allow for CFA duplicate analysis, but the sticks were not melted in a regular depth order so that instabilities in the measurement system could be more easily detected. As contamination cannot explain negative methane concentration anomalies, we could not find a convincing alternate explanation for layered bubble trapping in our results.

\subsection{Simple model of layered trapping}

A major difficulty for understanding the gas trapping in ice is to relate the structural properties measured in small samples to the three-dimensional behavior of the whole firn. For example, pore closure anomalies have been associated with tortuosity anomalies, with more tortuous layers closing earlier (Gregory et al., 2014), or to density anomalies, with denser layers closing earlier (Etheridge et al., 1992; Mitchell et al., 2015; Rhodes et al., 2016). In this section we used the latter hypothesis supported by observed relationships between local density and closed porosity (e.g., Stauffer et al., 1985; Mitchell et al., 2015) to test whether density-driven anomalies could result in artifacts as observed in the Vostok methane record.

In our simple model, the ice core is discretized in layers of $2 \mathrm{~cm}$ width. Abnormal layers are stochastically distributed along the ice core. Based on the characteristics of our Vostok methane signal, we use a density of 10 abnormal layers per meter. They are given a random density anomaly $(\Delta \rho$, normally distributed) representing the density variability at the bottom of the firn. Based on various sites, Hörhold et al. (2011) propose linear regressions in which the close-off den- 
sity variability declines for declining accumulation and temperature. Their lowest-accumulation site is Dome C, with

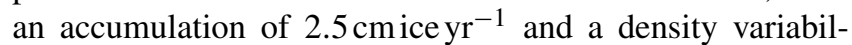
ity $(\Delta \rho)$ of $4.6 \mathrm{~kg} \mathrm{~m}^{-3}$. Applied to Vostok DO-17 conditions, the accumulation-based extrapolation leads to a variability of $7 \mathrm{~kg} \mathrm{~m}^{-3}$ and the temperature-based extrapolation leads to a variability of $2.7 \mathrm{~kg} \mathrm{~m}^{-3}$. This defines our extreme values $(7$ and $3 \mathrm{~kg} \mathrm{~m}^{-3}$ ), and we chose the middle number of $5 \mathrm{~kg} \mathrm{~m}^{-3}$ as the best-guess value. Hence, in the model, the abnormal layers are given a firn density anomaly distributed according to a zero-centered Gaussian distribution of standard deviation of $5 \mathrm{~kg} \mathrm{~m}^{-3}$. In order to convert density anomalies into a closure depth anomaly (the difference in pore closure depth between an abnormal layer and an adjacent layer following the bulk behavior), we assume that all layers have similar densification rates $(\mathrm{d} \rho / \mathrm{d} z)$. Using the data-based density profiles at Dome C, Vostok, and Dome A in Bréant et al. (2016), $\mathrm{d} \rho / \mathrm{d} z$ in deep firn is estimated to be in the range 1.7 to $2.5 \mathrm{~kg} \mathrm{~m}^{-4}$. Thus, the gradient is set to be $2 \mathrm{~kg} \mathrm{~m}^{-4}$. Specifically, a layer closing in advance (or late) closes higher (or lower) in the firn. Dividing the above typical density anomaly $(\Delta \rho)$ by the depth gradient $(\mathrm{d} \rho / \mathrm{d} z)$, the characteristic depth anomaly in deep firn of anomalous layers is about $2.5 \mathrm{~m}$. Using the

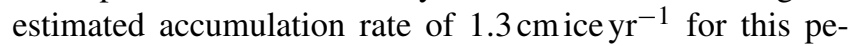
riod, it translates into an age anomaly (the gas age difference between an abnormal layer and an adjacent layer following the bulk behavior) of about 207 years. As explained in Sect. 4.1, late pore closure tends to produce weaker age anomalies than early closure due to the sealing of the surrounding firn. To take into account the lack of explicit gas transport in the model, we reduce the standard deviation of late closure age anomalies to 52 years, i.e., $25 \%$ of the value used for early closure artifacts. The value of $25 \%$ has been chosen to limit late trapping artifacts in a visually consistent manner with the observations. The methane mixing ratio at a given depth is computed using an atmospheric trend history and a gas age distribution (GAD) of trapped gases (Rommelaere et al., 1997). The atmospheric methane scenario used is the high-resolution methane record from the WAIS Divide ice core (Rhodes et al., 2015). The WDC gas age chronology (WD2014) was scaled to the GICC05 chronology (with present defined as 1950) dividing by a factor of 1.0063 as in Buizert et al. (2015). For the rest of the paper we use this scaled WD2014 chronology to express WDC gas ages. All layers are assumed to have the same GAD, simply centered on different ages. The GAD used here is the one derived in Sect. 5.2 specifically for the Vostok ice core during the DO-17 event. A sensitivity test using a very different GAD is described in the next paragraph. Finally, in order to reproduce the gas mixing in the CFA system discussed in Sect. 2.2, the modeled concentrations have been smoothed by convolving the signal with an estimated impulse response of the CFA system (Fig. S2). The smoothing characteristics of our measurement system were determined experimentally as in Stowasser et al. (2012). The CFA smoothing induces a damping of about $18 \%$ of the modeled artifacts.

The modeled artifacts (Fig. 4) globally reproduce the depth distribution and amplitude of the methane anomalies observed in the Vostok ice core (Fig. 1 and Sect. 4.2). To test the robustness and sensitivity of our model to uncertainties and underlying assumptions, we modified several model parameters. First, the limitation of late closure trapping was removed, hence simulating symmetrical behavior between early and late trapping. The results displayed in Fig. S7 show a clear increase in the amplitude of late closure artifacts. In particular, the enhanced late trapping produces artifacts of about $50 \mathrm{ppbv}$ before the onset of the DO-17 (in the 914 to $917 \mathrm{~m}$ depth range). Their absence in the CFA measurements confirms our assumption of the predominance of early closure artifacts. On the other hand, as shown in case B of Fig. 3, some limited late trapping is required to reproduce what appear as positive anomalies at the onset of the DO-17 event (912 to $913 \mathrm{~m}$ depth range). We also estimated the sensitivity of the model to the density variability $(\Delta \rho)$ and densification rate $(\mathrm{d} \rho / \mathrm{d} z)$. The extremal values for these two parameters provided at the beginning of this section result in typical depth anomalies of 1.2 and $4.1 \mathrm{~m}$, corresponding to age anomalies of 99 years and 341 years. The model results are displayed in Figs. S8 and S9. Using a reduced depth anomaly of the anomalous layers leads to largely reduced amplitudes of the anomalies. Using an increased depth anomaly of the anomalous layers leads to overestimated amplitudes of the anomalies, especially between 903 and $910 \mathrm{~m}$ of depth.

As using a Gaussian distribution of density anomalies is equivalent to using a random depth anomaly; the smallest anomalies produced by the model do not exceed the analytical noise. We imposed a density of 10 anomalies per meter, which results in about 5 significant anomalies per meter (exceeding $10 \mathrm{ppb}$ ) in the 895 to $915 \mathrm{~m}$ depth range. About $70 \%$ of these significant artifacts correspond to early closure layers. The width of the anomalous layers also influences the amplitude of the modeled anomalies because it is in the attenuation range of the CFA system. While $2 \mathrm{~cm}$ layers experience a damping of $18 \%$, an attenuation of about $30 \%$ is observed with $1 \mathrm{~cm}$ layers. The anomalies observed in the Vostok signal have widths ranging between 1 and a few centimeters. Their smoothing by the CFA system is thus limited. We also tested an alternative to the homogeneous GAD hypothesis, assuming that anomalous layers have a strongly reduced GAD similar to the gas age distribution in the WDC core. The results are displayed in Fig. S10. As the WDC record of the DO-17 event is less smooth than the Vostok record, the reduced GAD assumption leads to large positive artifacts, especially around $912 \mathrm{~m}$ of depth, which are not observed in the Vostok signal.

Finally, under the hypothesis of density-based layering, age anomalies strongly depend on accumulation as explained by Rhodes et al. (2016). A lower accumulation leads to a weaker density variability in the firn (Hörhold et al., 2011), 


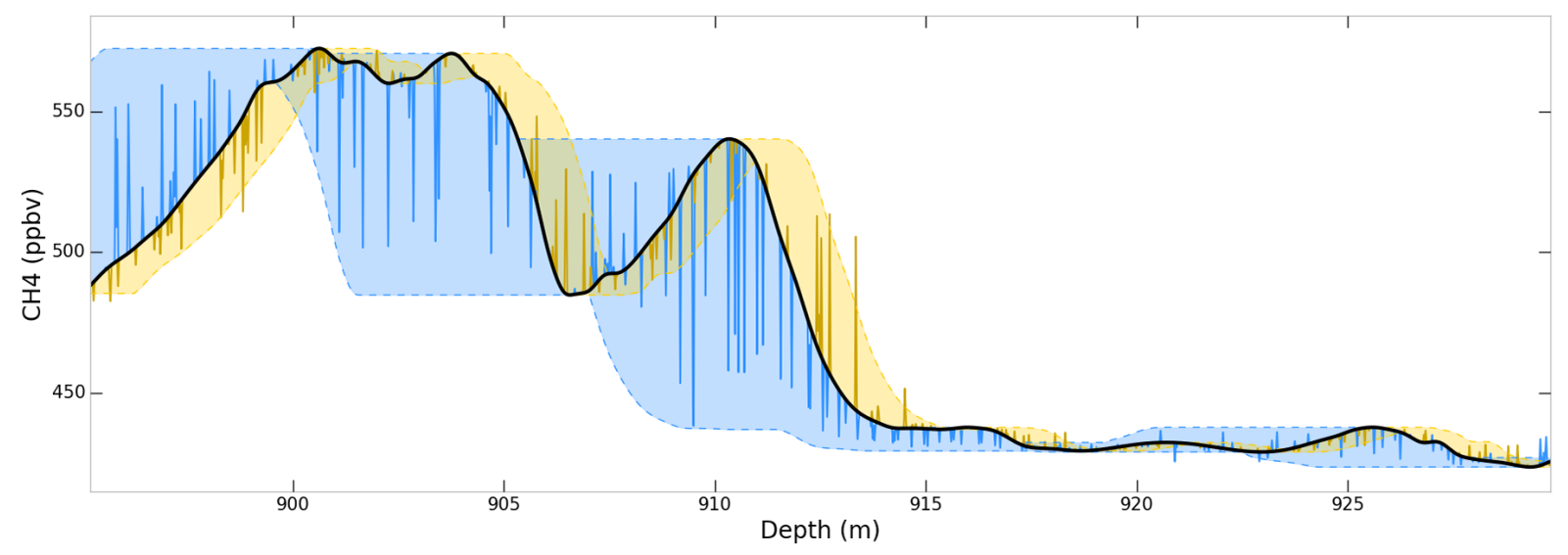

Figure 4. Modeled layered trapping artifacts. The black curve represents the results of smooth trapping. Spikes correspond to a single stochastic realization of the layered trapping with CFA smoothing. Blue stands for early closure and yellow for late closure. Blue shaded areas correspond to the range of concentration anomalies for early closure anomalies up to 2 standard deviations (depth anomaly of $5 \mathrm{~m}$ corresponding to an age anomaly of 415 years). Yellow shaded areas correspond to late closure anomalies with $25 \%$ of the early closure extent (depth anomaly of $1.25 \mathrm{~m}$ corresponding to an age anomaly of 104 years).

but at the same time leads to a larger age difference between successive firn layers due to a steeper age-depth slope. The second effect tends to dominate and the net effect of a lower accumulation is an increase in age anomalies due to layered trapping. Moreover, it is important to note that the good agreement between our density-driven model and observations does not imply that tortuosity is not an important factor in anomalous trapping. High-resolution air content measurements could potentially help us better understand the physical properties of anomalous layers at closure time.

\subsection{Removing layering artifacts in the methane record}

To extract an undisturbed (chronologically monotonous and representative of atmospheric variability only) methane signal from the Vostok 4G-2 core, layered trapping artifacts need to be removed from the high-resolution CFA record. Some sections of the core exhibit mainly positive or negative artifacts. Hence removing them using a running average would bias the signal. To account for this specificity, a cleaning algorithm has been developed. The underlying assumptions are that the chronological signal is a slowly varying signal with superimposed noise composed of the analytical noise and the layered trapping artifacts. Using a looping procedure, the artifacts are progressively trimmed until the resulting noise is free of spikes. The detailed algorithm is described in the following.

- Using the CFA signal (with or without already partially removed layering artifacts during the cleaning process) a running median is computed with a window of $15 \mathrm{~cm}$. Then a binned mean is computed with bins of $50 \mathrm{~cm}$. The goal of this step is to remove noise without introducing a bias due to layering artifacts.
- A spline of degree 3 is used to interpolate between the binned points on the original CFA depth scale. This interpolating spline does not further smooth the signal and is used as an approximation of the chronologically monotonous signal, free of layering artifacts.

- By removing the spline from the CFA signal we obtain the detrended noise of the signal composed of the analytical noise and the remaining artifacts.

- We then compute the normalized median absolute deviation (NMAD) of the detrended noise. The expression of the NMAD is $1.4826 \times \operatorname{med}\left(\left|x_{i} \operatorname{med}\left(x_{i}\right)\right|\right)$, where $x_{i}$ represents the noise values and "med" the median. This is a robust estimator of variability, weakly sensitive to outliers (Höhle and Höhle, 2009; Rousseeuw and Hubert, 2011). It enables the estimation of the variability of the noise without the artifacts, i.e., the analytical noise.

- The detrended noise is cut off with a threshold of 2.5 times the NMAD.

- We then check whether the noise is free of spikes. For this we compare the NMAD (estimation of the variability without spikes) and the standard deviation (estimation of variability with spikes) of the detrended noise. If these two quantities are similar, the noise is free of anomalous layers. Once the standard deviation is lower than 1.5 times the NMAD, the procedure is finished. Otherwise, the algorithm is looped.

This algorithm does not require an estimation of the analytical noise beforehand, since this value is dynamically computed. However, it is sensitive to the value of 1.5 used to compare the NMAD and standard deviation to test for 
Table 1. Layering model parameters and resulting depth anomaly, age anomaly, and associated figure. The first row corresponds to the reference simulation and the sensitivity tests are below. The depth and age anomaly values refer to the standard deviation $(1 \sigma)$ of early trapping artifacts. These $1 \sigma$ values are half the $2 \sigma$ values mentioned in the corresponding figure captions.

\begin{tabular}{lllllll}
\hline $\begin{array}{l}\mathrm{d} \rho / \mathrm{d} z^{-4} \\
\left(\mathrm{~kg} \mathrm{~m}^{-4}\right)\end{array}$ & $\begin{array}{l}\Delta \rho \\
\left(\mathrm{kg} \mathrm{m}^{-3}\right)\end{array}$ & $\begin{array}{l}\text { Limit late } \\
\text { anomalies }\end{array}$ & $\begin{array}{l}\text { Narrow } \\
\text { GADs }\end{array}$ & $\begin{array}{l}\text { Depth anomaly } \\
(\mathrm{m})\end{array}$ & $\begin{array}{l}\text { Age anomaly } \\
(\mathrm{yr})\end{array}$ & Figure \\
\hline 2 & 5 & Yes & No & 2.5 & 207 & 4 \\
2 & 5 & No & No & 2.5 & 207 & $\mathrm{~S} 7$ \\
2.5 & 3 & Yes & No & 1.2 & 99 & S8 \\
1.7 & 7 & Yes & No & 4.1 & 341 & S9 \\
2 & 5 & Yes & Yes & 2.5 & 207 & S10 \\
\hline
\end{tabular}

the presence of artifacts. The remaining signal after cutting off the layered trapping anomalies has a noise amplitude of $\pm 16 \mathrm{ppbv}$ and is represented in black in Fig. 1. With our method $15 \%$ of the methane data points have been removed. As expected, the signal is almost unmodified below $915 \mathrm{~m}$, with a portion of removed points of only $1.3 \%$. On the other hand, the variability above $915 \mathrm{~m}$ is greatly reduced and about $26 \%$ of the methane data points have been removed.

\section{Smoothing and age distribution in the Vostok 4G-2 ice core}

\subsection{The smoothing of the methane record}

Once the methane signal is cleaned from layered trapping artifacts, we consider the data to be a chronologically ordered and unbiased signal recorded in the core. It is smoothed (high frequencies are damped) with respect to the true atmospheric signal and can be used to infer the degree of smoothing in the Vostok ice core. The damping can be visualized in Fig. 5 by comparing the Vostok record with the WDC record. High-frequency atmospheric variability is much better preserved in the WAIS Divide ice core because the accumulation rate is more than an order of magnitude higher (in the range from 18 to $22 \mathrm{~cm}^{\text {ice }} \mathrm{yr}^{-1}$ for the studied period; Buizert et al., 2015), and thus the firn densification and gas trapping are faster. For instance, the methane variation spanning between 59000 and $58800 \mathrm{yr} \mathrm{BP}$ is damped by $\sim 50 \%$ in the Vostok record compared to WDC. Moreover, a 20 ppbv subcentennial variation is present in the WDC record between 58700 and $58600 \mathrm{yrBP}$. In the Vostok record, however, this short-scale variability event has been smoothed out. On the other hand the multi-centennial variability visible between 58700 and $58400 \mathrm{yr}$ BP is well preserved with only a slight damping. From the comparison between WDC and Vostok, we can infer that the smoothing in Vostok 4G-2 prevents us from retrieving information below the centennial scale during the DO-17 period.

\subsection{Estimate of the gas age distribution}

The smoothing of gas concentrations in ice core records is the direct consequence of the broad gas age distributions in the ice (Spahni et al., 2003; Joos and Spahni, 2008; Köhler et al., 2011; Ahn et al., 2014). We call absolute GAD the age distribution expressed on an absolute timescale in years before present. The relative GAD is the distribution expressed relatively to its mean age. For a given layer, absolute and relative GAD thus only differ by a translation in age. Here we assume that all layers densified under the same physical conditions hence share the same relative GAD. Since computing concentrations along an ice core using GADs is equivalent to a convolution product (Rommelaere et al., 1997), the resulting concentrations will be called convolved signals.

The climatic conditions of the glacial period on the Antarctic plateau have no modern analogue, and thus relevant GADs cannot be inferred from modern firn observations. High-resolution CFA-based gas records offer a new opportunity to estimate GADs without modern analogue. We thus developed such a method, which requires a reference atmospheric scenario with much higher frequencies resolved. The method can be extended to gases other than methane or to low-accumulation records other than the Vostok 4G-2 core. The principle of the method is to determine a GAD able to convolve the high-accumulation record (in our case, WAIS Divide) into a smoothed signal that minimizes the differences with the observed low-accumulation record (in our case, Vostok). It can be seen as an inverse problem. Two assumptions are made to reduce the number of adjusted parameters and thus ensure that the problem is well defined in a mathematical sense. First, all ice layers have the same relative GAD over the considered period. Second, following Köhler et al. (2011), this relative GAD is assumed to be a lognormal distribution that is fully characterized by two free parameters (for instance, its mean and standard deviation). Due to the asymmetry of the GAD, the resulting convolved signal displays age shifts when compared with the original atmospheric scenario. Hence for a valid comparison between the record and convolved signals, it is necessary to modify the age scale and to optimize the GAD in an iterative process. Using an initial age scale, the steps are as follows. 


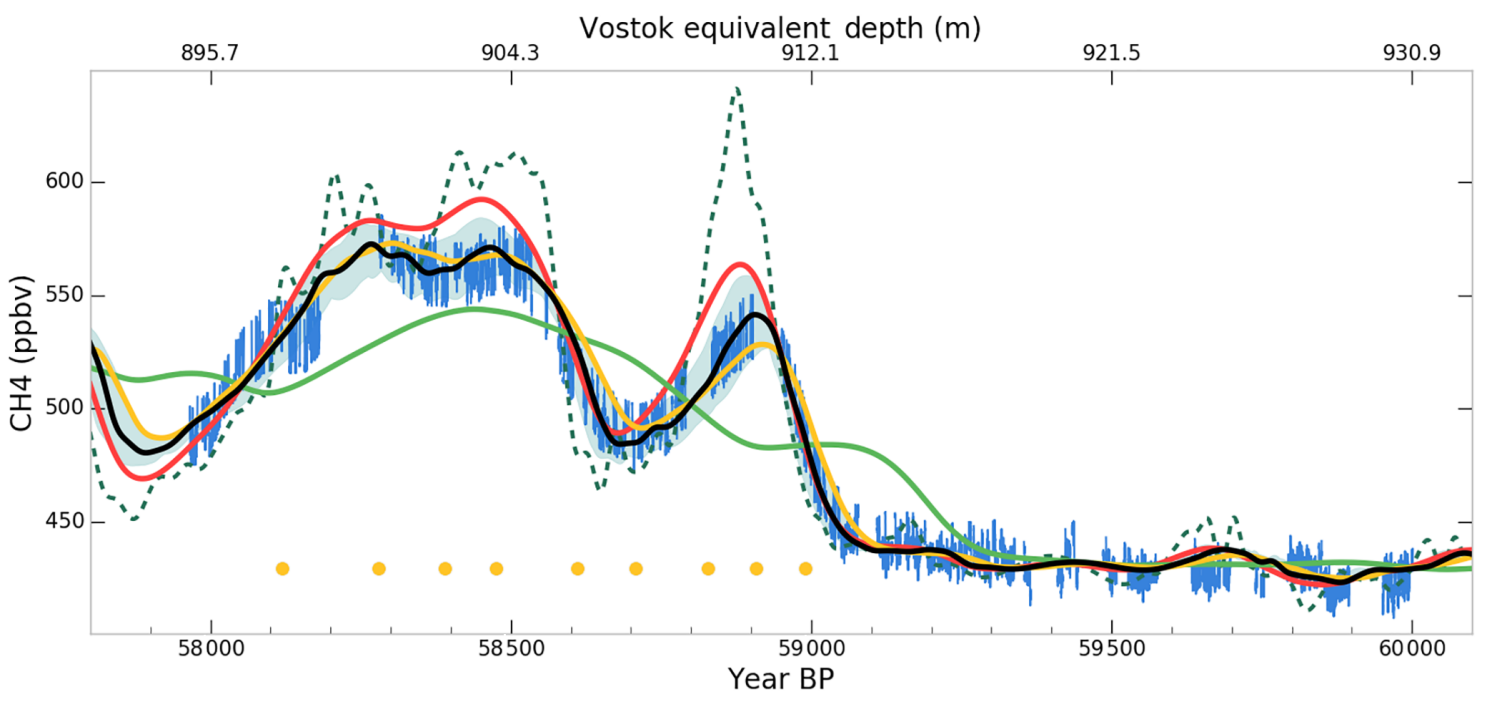

Figure 5. WDC $\mathrm{CH}_{4}$ signal convolved with different GADs: the Dome C GAD estimated for the Bølling-Allerød by Köhler et al. (2015) in red, the Dome C GAD estimated for the Last Glacial Maximum by Köhler et al. (2011) in green, a lognormal fit to the modern Vostok GAD from Witrant et al. (2012) in yellow, and the Vostok DO-17 GAD estimated in Sect. 5.2 in black (uncertainty envelope shown in light blue). The WDC record (Rhodes et al., 2015) is displayed in dashed green, and the CFA Vostok measurements in blue. Yellow dots show the tie points used to match the WDC and Vostok records.

1. First, a new gas age scale is derived. Tie points are manually selected between the low-accumulation record and the convolved high-accumulation record. The tie points we selected correspond to minima, maxima, and midslopes points of the methane record. For the initialization, since no GAD has been optimized yet, we use the atmospheric scenario instead of the convolved signal. The new gas chronology is then generated by interpolation and extrapolation between tie points.

2. A new lognormal GAD is optimized by modifying its two parameters in order to minimize differences between the simulated and observed smoothed signals. We performed this optimization with a differential evolution algorithm (Storn and Price, 1997).

3. If the definition of a new chronology and a new GAD does not improve the RMSD (root mean square deviation) between the convolved signal and the measurements five times in a row, then the algorithm is stopped.

The above methodology can be applied to different ice drilling sites. Here we describe the specific aspects to match the Vostok record with WDC. Rhodes et al. (2015) state the following: "Only at gas ages $>60 \mathrm{kaBP}$ is there a possibility that the continuous measurement system caused dampening of the $\mathrm{CH}_{4}$ signal greater than that already imparted by firn-based smoothing processes". Moreover, Fig. S1 of the supplement to Rhodes et al. (2015) predicts a GAD width of about 40 years for the DO-17 event, which is much smaller than the width of the Vostok GAD. This ensures that the WDC signal resolves enough high frequencies to be used as the weakly smoothed atmospheric scenario compared to the Vostok record and that the convolving function given by the algorithm is close to the actual Vostok GAD. As explained in Sect. 4.2, the WD2014 gas chronology is converted to the GICC05 scale (Buizert et al., 2015) and not further modified. The algorithm only adjusts the Vostok gas ages, which remain well within AICC2012 uncertainties. The initial gas ages used are the ones derived from nitrogen isotope measurements in Sect. 3.2, and the optimization has been performed on data ranging from 900 to $915 \mathrm{~m}$ of depth. This depth interval has been chosen since it corresponds to a significantly dampened event in the Vostok record, which is sensitive to the choice of the GAD. The optimized gas age distribution is displayed in Fig. 6 in black, with uncertainty intervals shown as light blue shaded area. The uncertainty envelope encloses all the distributions resulting in simulated Vostok signals with an RMSD from the measurements lower than $150 \%$ of the optimal RMSD. The optimal lognormal parameters are given in Table 2 . The chosen tie points are displayed in Fig. 5, and the optimized $\Delta$ Age values along the Vostok core are depicted in green in Fig. 2. The optimal convolution of the WDC methane record from Rhodes et al. (2015) into a Vostok signal can be seen in black in Fig. 5, with the impact of the uncertainty on the GAD displayed as the light blue envelope. The convolution fits the methane measurements within the analytical noise. The overall consistency between the measured and simulated Vostok signals confirms that the Vostok record is a smoothed version of the WDC record and that the choice of a single GAD for the whole DO-17 record is a credible hypothesis. This last point is consistent with the fairly stable climatic conditions on the Antarctic plateau over 
this time period (Petit et al., 1999; Bazin et al., 2013; Veres et al., 2013).

\section{Discussion}

\subsection{Understanding the smoothing of ice core signals under low-accumulation conditions}

In Fig. 6, our GAD adjusted to produce the expected smoothing rate for the DO-17 event in the Vostok ice core (in black) is compared to other available gas age distributions for lowaccumulation-rate conditions. The different parameters of the lognormal GADs used in this section are displayed in Table 2. For modern ice cores, GADs can be estimated with gas transport models constrained by firn air composition data (Buizert et al., 2012; Witrant et al., 2012). However, the results directly depend on the closed versus total porosity parameterization used, which is insufficiently constrained (e.g., Mitchell et al., 2015). We performed a comparison of our optimized GAD for Vostok during DO-17 with the lognormal fit to a GAD constrained with modern-condition firn air measurements at Vostok (Witrant et al., 2012, in yellow in Fig. 6). Note that using the modern GAD from Witrant et al. (2012) or a lognormal fit to this GAD leads to the same smoothing, but the lognormal GAD enables us to provide simple GAD parameters in Table 2. The comparison with our optimized DO-17 GAD suggests a slightly narrower distribution for the glacial period, despite lower temperatures. On the other hand, the GAD estimate from Köhler et al. (2015) for Dome $\mathrm{C}$ during the $\mathrm{B} \varnothing$ lling-Allerød (B/A; accumulation of

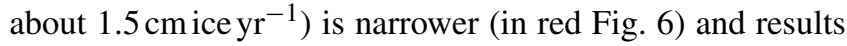
in a slightly too-weakly smoothed methane record in Fig. 5. Finally, the GAD proposed by Köhler et al. (2011) for Dome $\mathrm{C}$ during the Last Glacial Maximum (LGM) is broader than the other presented GADs (in green Fig. 6) and thus leads to a stronger smoothing in the record in Fig. 5. The GADs calculated for modern conditions from Köhler et al. (2011) at Dome C and Witrant et al. (2012) at Vostok are very similar, which is consistent with the comparable accumulation rates

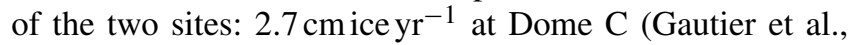
2016) and $2.4 \mathrm{~cm}$ ice $\mathrm{yr}^{-1}$ at Vostok (Arnaud et al., 2000). We therefore do not observe a systematic broadening of GADs for lower accumulation rates, even at a given site. This questions either the relationship between GAD widths and accumulation rate or the consistency between GADs derived from gas transport models in firn and the GAD obtained with our method of record comparison.

The most likely reason for an inconsistency between GADs inferred from firn models and from CFA data is the large uncertainty in the representation of gas trapping in firn models. As mentioned above, the closed versus total porosity ratio is very uncertain, as it was measured only at a few sites and in small size samples. Better constraints on the physics of gas trapping would thus be helpful. However, there is no modern analogue of the central Antarctic plateau sites (such
Table 2. Parameters defining the lognormal distributions used as GADs for Vostok DO-17 (this study), lognormal fit to modern Vostok (Witrant et al., 2012), Dome C during the Bølling-Allerød (Dome C B/A; Köhler et al., 2015), and Dome C during the Last Glacial Maximum (Dome C LGM; Köhler et al., 2011). Location and scale respectively refer to the parameters $\mu$ and $\sigma$ used in Eq. (1) in Köhler et al. (2011). SD stands for standard deviation.

\begin{tabular}{lrrrr}
\hline $\begin{array}{l}\text { Site and } \\
\text { period }\end{array}$ & Location & Scale & $\begin{array}{r}\text { Mean } \\
(\mathrm{yr})\end{array}$ & $\begin{array}{r}\text { SD } \\
(\mathrm{yr})\end{array}$ \\
\hline Vostok DO-17 & 4.337 & 1.561 & 259 & 835 \\
Vostok modern & 4.886 & 1.029 & 226 & 308 \\
Dome C B/A & 4.886 & 0.5 & 150 & 79 \\
Dome C LGM & 5.880 & 1 & 590 & 773 \\
\hline
\end{tabular}

as Vostok or Dome C) under glacial conditions. Thus, using CFA high-resolution gas measurements at different sites to constrain Holocene GADs at low-accumulation sites would be the only way to check the consistency of the two methods. Previous comparisons between sites indicate that the smoothing is larger for low-accumulation conditions (Spahni et al., 2003; Joos and Spahni, 2008; Köhler et al., 2011; Ahn et al., 2014). Indeed, a simple argument is that the lower the accumulation and the temperature, the slower a firn layer will densify, and thus the broader the GAD. The comparison of the DO-17 records between WDC and Vostok 4G-2 corroborates this relationship: the higher-accumulation WDC signal is less smooth than the Vostok signal (Fig. 5).

The weaker-than-expected smoothing during DO-17 at Vostok could be due to the presence of a strong layering preventing air renewal and mixing, as suggested in Mitchell et al. (2015).

From a paleoclimatic point of view, an important conclusion of this work is that the smoothing of atmospheric trace gases recorded in ice cores from the central Antarctic plateau could be less than expected under glacial conditions, resulting in more retrievable information about past atmospheric conditions. Ice cores with the oldest enclosed gases, such as in the Oldest Ice project (Fischer et al., 2013), will be retrieved from very low-accumulation sites. They could thus potentially provide meaningful information down to the multi-centennial scale.

\subsection{Layered trapping and atmospheric trend reconstructions}

The anomalous layers in the Vostok methane record discussed in Sect. 4.2 are 1 to a few centimeters thick, and discrete samples used for methane measurements in ice cores are typically also a few centimeters thick. In our study, the use of high-resolution continuous analysis made it possible to identify abnormal methane values that appeared as spikes in the record. However, in the case of discrete measurements, the absence of continuous information makes it hard 


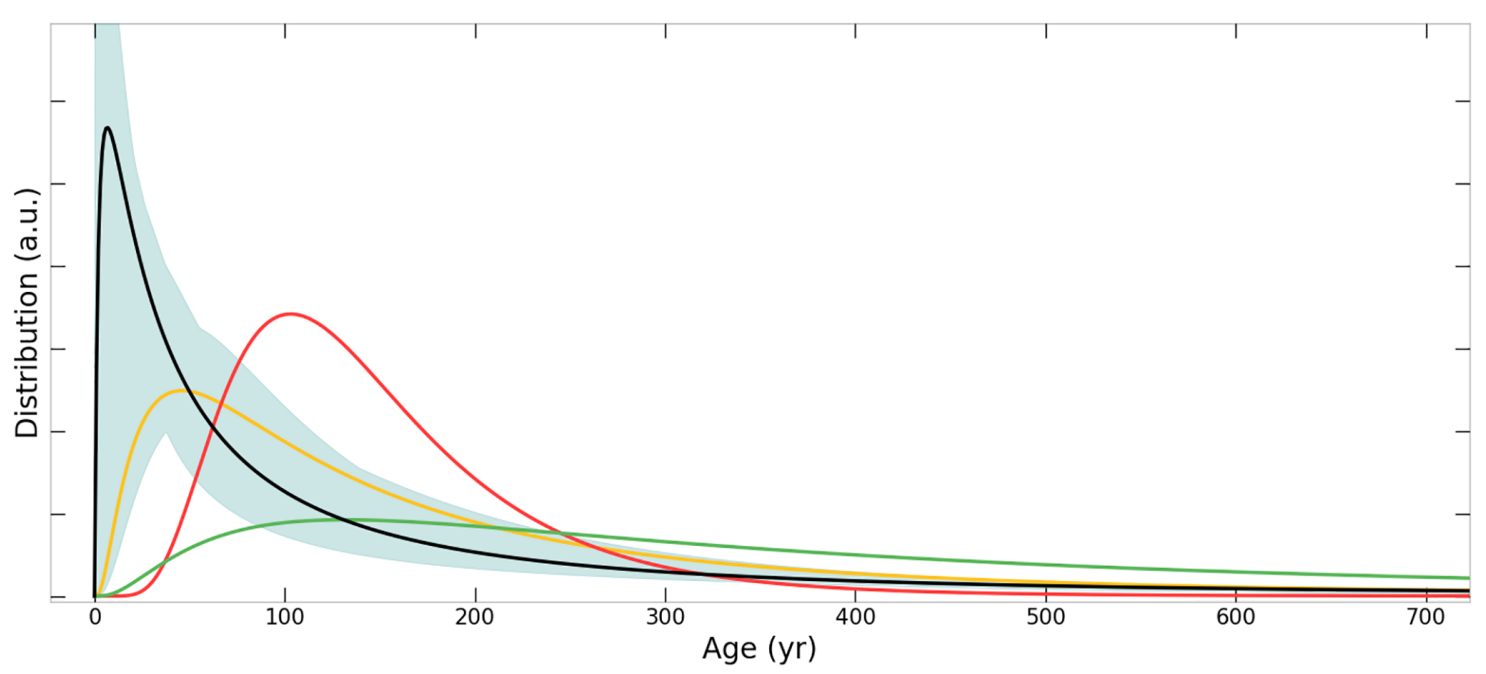

Figure 6. Gas age distributions. In black: the Vostok GAD during the DO-17 estimated with our optimization scheme; the uncertainty envelope is shown in light blue. In yellow: a lognormal fit to the modern-condition Vostok GAD from Witrant et al. (2012). In red: the estimated Dome C GAD during B/A from Köhler et al. (2015). In green: the estimated Dome C GAD during LGM from Köhler et al. (2011).

to discriminate between normal and abnormal layers. For instance, the comparison of the WDC continuous record and the EPICA Dome C (EDC) discrete methane record (Loulergue et al., 2008) indicates a potential artifact during the onset of the Dansgaard-Oeschger event 8 ( $238000 \mathrm{yr} \mathrm{BP})$, as displayed in Fig. 7. One of the EDC samples shows a reduced methane concentration, which should be visible in the less smooth WDC record as well if this corresponded to a true atmospheric feature. Moreover, the measured mixing ratio in this EDC sample is consistent with an artifact resulting from early gas trapping. As mentioned in Rhodes et al. (2016) and confirmed by our study, it is important for paleoclimatic studies to avoid interpreting such abnormal values as fast atmospheric events.

However, continuous-flow analysis may not always allow us to distinguish between layering artifacts and the chronologically ordered signal. The deep parts of ice cores with low accumulation and high thinning are of particular interest in paleoclimatology since they enclose very old gases (Loulergue et al., 2008; Lüthi et al., 2008). However, with a strong thinning, the width of abnormal layers may shrink below the spatial resolution limit of analytical systems. In such a case, an average mixing ratio over several layers is measured. Since layered trapping artifacts are unevenly distributed in terms of sign, they bias the measured average signal. In the very simple case of a record with artifacts that are all negatively orientated, cover $15 \%$ of the ice core, and all reach $50 \mathrm{ppbv}$, this bias is about $-7 \mathrm{ppbv}$. In the case of records with lower accumulation or stronger methane variations the bias will be even more important. The development of very high-resolution gas measurement techniques thus offers important perspectives for analyzing the deepest part of ice cores. In intermediate situations in which anomalous lay-

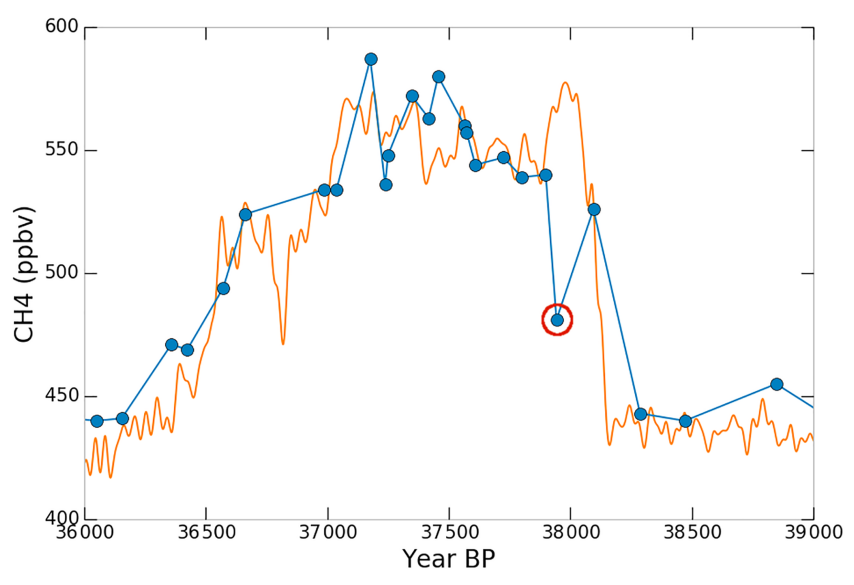

Figure 7. Discrete EDC methane record (blue) and continuous WDC methane record (orange). The WDC record was put on the GICC05 timescale and then shifted by 250 years to improve matching. We suggest that the circled point corresponds to a layered trapping artifact.

ers could be distinguished but a high-accumulation record is not available (before the last glacial-interglacial cycle), the effect of smoothing is more difficult to constrain, but the presence of layered trapping artifacts is in itself an indication that some smoothing may occur because layered trapping occurs only under fast atmospheric change conditions.

\section{Conclusions}

We presented the first very high-resolution record of methane in an ice core sequence formed under very lowaccumulation-rate conditions. It covers the gas record of 
Dansgaard-Oeschger event 17 , chosen for its abrupt atmospheric methane changes on a similar timescale as gas trapping.

The continuous-flow analysis system, optimized to reduce gas mixing, allowed us to reveal numerous centimeter-scale methane concentration anomalies. Positive anomalies affecting both the methane and carbon monoxide records were attributed to kerosene contamination and discarded. The remaining anomalies are unevenly distributed, a few centimeters wide, and mostly negatively oriented with dips as low as $-50 \mathrm{ppbv}$. The anomalies occur only during time periods of fast atmospheric methane variability. The main characteristics of the size and distribution of the anomalies could be reproduced with a simple model based on relating realistic firn density anomalies to early or (to a lesser extent) late trapping. Such layered trapping anomalies may be confused with the climatic signal in discrete climate records or bias the signal if too narrow to be detected by a CFA system (e.g., under the high-thinning conditions of the deep part of ice cores). It is important for future paleoclimatic studies not to interpret those abrupt variations as fast chronologically ordered atmospheric variations. Further use of high-resolution continuous analysis will allow us to discriminate layered trapping artifacts and to better identify their statistical characteristics. Moreover, the sign of the trapping artifacts is not random: some sections of the record display only positive or negative artifacts. Thus, simple averaging would result in a systematic bias of the signal. Hence, we developed a cleaning algorithm aiming at minimizing this bias.

After removing the centimeter-scale anomalies, the remaining Vostok methane signal is distinctly smoother than the WDC record (Rhodes et al., 2015). The snow accumulation rate being more than 1 order of magnitude higher at WDC than at Vostok, the WDC signal contains higherfrequency features. The comparison of the two signals opens the possibility to estimate gas age distributions for conditions of the East Antarctic plateau during the last glacial period, which have no modern analogue. For the DO-17 event at Vostok, the resulting gas age distribution is narrower than expected from a comparison with modern firns (Köhler et al., 2011; Witrant et al., 2012). It may be due to an incorrect prediction of gas trapping by firn models and/or an incorrect extrapolation of the firn behavior to very lowtemperature and low-accumulation conditions. The apparently similar smoothing at Vostok under DO-17 and present conditions contradicts the expected primary effect of temperature and accumulation rate: lower temperature and accumulation rates induce a longer gas trapping duration and thus a stronger smoothing.

On the other hand, Mitchell et al. (2015) point out the lack of firn layering representation in most firn models and conclude that firn layering narrows gas age distribution in ice. From a paleoclimatic point of view, ice cores with the lowest accumulations contain very old gases. The smoothing under glacial conditions being less important than expected implies that atmospheric information on a shorter timescale than previously expected might be retrieved. However, similar measurements need to be performed on other low-accumulation records to confirm our results for different sites and/or periods. For the DO-17 event at Vostok, multi-centennial atmospheric variations are still accessible in the record. Further comparisons of high- and low-accumulation records of the last glacial cycle will allow us to better constrain the relationship between ice cores and atmospheric gas signals, even with no modern analogue conditions.

Code availability. Numerical codes were developed using Python 2.7 and readily available packages (numpy, scipy, etc.). They will be provided upon direct request to the corresponding authors.

Data availability. Data sets produced during this study are available in the World Data Center for Paleoclimatology (WDC Paleo; https://www.ncdc.noaa.gov/paleo-search/study/23210).

\section{The Supplement related to this article is available online at https://doi.org/10.5194/cp-13-1815-2017-supplement.}

Author contributions. Methane measurements were carried out by XF and KF. Nitrogen isotope measurements were carried out by KF and AL. Numerical codes were designed and developed by KF and PM. The ice core samples were made available thanks to VYaL and JC. They were cut and sent to France from Vostok station by AAE. All coauthors contributed to the data analysis and interpretation. The paper was written by KF with the help of all coauthors.

Competing interests. The authors declare that they have no conflict of interest.

Acknowledgements. The research leading to these results received funding from the European Community Seventh Framework Programme ERC2011 under grant agreement no. 291062 (ERC Ice\&Lasers), the INSU/CNRS LEFE project NEVE-CLIMAT, the Laboratoire International Associé Vostok partnership, the LabEx OSUG@2020 (Investissements d'avenir - ANR10LABX56), and the École Normale Supérieure Paris-Saclay. Ice core samples were made available within the Laboratoire International Associé Vostok partnership. We are grateful to the Russian Antarctic Expeditions for carrying out the logistics and the shipping of the ice core samples to Europe. We also thank Frédéric Prié for his help during nitrogen isotope measurements and Maurine Montagnat and Cédric Lachaud for their help with the thin sections. Finally, we thank Hubertus Fischer and the two anonymous referees for their constructive and helpful comments on this paper. 
Edited by: Hubertus Fischer

Reviewed by: two anonymous referees

\section{References}

Ahn, J., Brook, E. J., and Buizert, C.: Response of atmospheric $\mathrm{CO}_{2}$ to the abrupt cooling event 8200 years ago, Geophys. Res. Lett., 41, 604-609, https://doi.org/10.1002/2013g1058177, 2014.

Allan, D. W.: Statistics of atomic frequency standards, Proc. IEEE, 54, 221-230, https://doi.org/10.1109/proc.1966.4634, 1966.

Arnaud, L., Barnola, J.-M., and Duval, P.: Physical modeling of the densification of snow/firn and ice in the upper part of polar ice sheets, Physics of Ice Core Records, 285-305, http://hdl.handle. net/2115/32472 (last access: 28 November 2017), 2000.

Bazin, L., Landais, A., Lemieux-Dudon, B., Toyé Mahamadou Kele, H., Veres, D., Parrenin, F., Martinerie, P., Ritz, C., Capron, E., Lipenkov, V. Y., Loutre, M.-F., Raynaud, D., Vinther, B., Svensson, A., Rasmussen, S. O., Severi, M., Blunier, T., Leuenberger, M., Fischer, H., Masson-Delmotte, V., Chappellaz, J., and Wolff, E. W.: An optimized multi-proxy, multi-site Antarctic ice and gas orbital chronology (AICC2012): 120-800 ka, Clim. Past, 9, 1715-1731, https://doi.org/10.5194/cp-9-1715-2013, 2013.

Bender, M. L., Sowers, T., Barnola, J.-M., and Chappellaz, J.: Changes in the $\mathrm{O}_{2} / \mathrm{N}_{2}$ ratio of the atmosphere during recent decades reflected in the composition of air in the firn at Vostok Station, Antarctica, Geophys. Res. Lett., 21, 189-192, https://doi.org/10.1029/93g103548, 1994.

Bigler, M., Svensson, A., Kettner, E., Vallelonga, P., Nielsen, M. E., and Steffensen, J. P.: Optimization of high-resolution continuous flow analysis for transient climate signals in ice cores, Envir. Sci. Tech., 45, 4483-4489, https://doi.org/10.1021/es200118j, 2011.

Bréant, C., Martinerie, P., Orsi, A., Arnaud, L., and Landais, A.: Modelling firn thickness evolution during the last deglaciation: constraints on sensitivity to temperature and impurities, Clim. Past, 13, 833-853, https://doi.org/10.5194/cp-13-8332017, 2016.

Brook, E. J., Sowers, T., and Orchardo, J.: Rapid variations in atmospheric methane concentration during the past 110,000 years, Science, 273, 1087-1091, https://doi.org/10.1126/science.273.5278.1087, 1996.

Buizert, C., Martinerie, P., Petrenko, V. V., Severinghaus, J. P., Trudinger, C. M., Witrant, E., Rosen, J. L., Orsi, A. J., Rubino, M., Etheridge, D. M., Steele, L. P., Hogan, C., Laube, J. C., Sturges, W. T., Levchenko, V. A., Smith, A. M., Levin, I., Conway, T. J., Dlugokencky, E. J., Lang, P. M., Kawamura, K., Jenk, T. M., White, J. W. C., Sowers, T., Schwander, J., and Blunier, T.: Gas transport in firn: multiple-tracer characterisation and model intercomparison for NEEM, Northern Greenland, Atmos. Chem. Phys., 12, 4259-4277, https://doi.org/10.5194/acp12-4259-2012, 2012.

Buizert, C., Cuffey, K. M., Severinghaus, J. P., Baggenstos, D., Fudge, T. J., Steig, E. J., Markle, B. R., Winstrup, M., Rhodes, R. H., Brook, E. J., Sowers, T. A., Clow, G. D., Cheng, H., Edwards, R. L., Sigl, M., McConnell, J. R., and Taylor, K. C.: The WAIS Divide deep ice core WD2014 chronology-Part 1: methane synchronization (68-31 ka BP) and the gas age-ice age difference, Clim. Past, 11, 153-173, https://doi.org/10.5194/cp11-153-2015, 2015.
Chappellaz, J., Barnola, J.-M., Raynaud, D., Korotkevich, Y. S., and Lorius, C.: Ice-core record of atmospheric methane over the past 160,000 years, Nature, 345, 127-131, https://doi.org/10.1038/345127a0, 1990.

Chappellaz, J., Stowasser, C., Blunier, T., Baslev-Clausen, D., Brook, E. J., Dallmayr, R., Faïn, X., Lee, J. E., Mitchell, L. E., Pascual, O., Romanini, D., Rosen, J., and Schüpbach, S.: High-resolution glacial and deglacial record of atmospheric methane by continuous-flow and laser spectrometer analysis along the NEEM ice core, Clim. Past, 9, 2579-2593, https://doi.org/10.5194/cp-9-2579-2013, 2013.

Colbeck, S. C.: Air movement in snow due to windpumping, J. Glaciol., 35, 209-213, https://doi.org/10.1017/S0022143000004524, 1989.

Craig, H., Horibe, Y., and Sowers, T.: Gravitational separation of gases and isotopes in polar ice caps, Science, 242, 1675-1678, https://doi.org/10.1126/science.242.4886.1675, 1988.

Dlugokencky, E. J., Myers, R. C., Lang, P. M., Masarie, K. A., Crotwell, A. M., Thoning, K. W., Hall, B. D., Elkins, J. W., and Steele, L. P.: Conversion of NOAA atmospheric dry air $\mathrm{CH}_{4}$ mole fractions to a gravimetrically prepared standard scale, J. Geophys. Res.-Atmos., 110, D18306, https://doi.org/10.1029/2005jd006035, 2005.

Etheridge, D. M., Pearman, G. I., and Fraser, P. J.: Changes in tropospheric methane between 1841 and 1978 from a high accumulation-rate Antarctic ice core, Tellus B, 44, 282-294, https://doi.org/10.3402/tellusb.v44i4.15456, 1992.

Faïn, X., Chappellaz, J., Rhodes, R. H., Stowasser, C., Blunier, T., McConnell, J. R., Brook, E. J., Preunkert, S., Legrand, M., Debois, T., and Romanini, D.: High resolution measurements of carbon monoxide along a late Holocene Greenland ice core: evidence for in situ production, Clim. Past, 10, 987-1000, https://doi.org/10.5194/cp-10-987-2014, 2014.

Fischer, H., Severinghaus, J., Brook, E., Wolff, E. W., Albert, M., Alemany, O., Arthern, R., Bentley, C., Blankenship, D., Chappellaz, J., Creyts, T., Dahl-Jensen, D., Dinn, M., Frezzotti, M., Fujita, S., Gallee, H., Hindmarsh, R., Hudspeth, D., Jugie, G., Kawamura, K., Lipenkov, V. Y., Miller, H., Mulvaney, R., Parrenin, F., Pattyn, F., Ritz, C., Schwander, J., Steinhage, D., van Ommen, T., and Wilhelms, F.: Where to find 1.5 million yr old ice for the IPICS “Oldest-Ice" ice core, Clim. Past, 9, 2489-2505, https://doi.org/10.5194/cp-9-2489-2013, 2013.

Fujita, S., Goto-Azuma, K., Hirabayashi, M., Hori, A., Iizuka, Y., Motizuki, Y., Motoyama, H., and Takahashi, K.: Densification of layered firn in the ice sheet at Dome Fuji, Antarctica, J. Glaciol., 62, 103-123, https://doi.org/10.1017/jog.2016.16, 2016.

Gautier, E., Savarino, J., Erbland, J., Lanciki, A., and Possenti, P.: Variability of sulfate signal in ice core records based on five replicate cores, Clim. Past, 12, 103-113, https://doi.org/10.5194/cp12-103-2016, 2016.

Gregory, S. A., Albert, M. R., and Baker, I.: Impact of physical properties and accumulation rate on pore close-off in layered firn, The Cryosphere, 8, 91-105, https://doi.org/10.5194/tc-8-912014, 2014.

Höhle, J. and Höhle, M.: Accuracy assessment of digital elevation models by means of robust statistical methods, ISPRS J. Photogramm., 64, 398-406, https://doi.org/10.1016/j.isprsjprs.2009.02.003, 2009. 
Hörhold, M. W., Kipfstuhl, S., Wilhelms, F., Freitag, J., and Frenzel, A.: The densification of layered polar firn, J. Geophys. Res.-Earth, 116, F01001, https://doi.org/10.1029/2009jf001630, 2011.

Joos, F. and Spahni, R.: Rates of change in natural and anthropogenic radiative forcing over the past 20,000 years, P. Natl. Acad. Sci. USA, 105, 1425-1430, https://doi.org/10.1073/pnas.0707386105, 2008.

Jouzel, J., Masson-Delmotte, V., Cattani, O., Dreyfus, G., Falourd, S., Hoffmann, G., Minster, B., Nouet, J., Barnola, J.-M., Chappellaz, J., Fischer, H., Gallet, J. C., Johnsen, S., Leuenberger, M., Loulergue, L., Lüuthi, D., Oerter, H., Parrenin, F., Raisbeck, G., Raynaud, D., Schilt, A., Schwander, J., Selmo, E., Souchez, R., Spahni, R., Stauffer, B., Steffensen, J. P., Stenni, B., Stocker, T. F., Tison, J. L., Werner, M., and Wolff, E. W.: Orbital and millennial antarctic climate variability over the past 800,000 years, Science, 317, 793-796, https://doi.org/10.1126/science.1141038, 2007.

Köhler, P., Knorr, G., Buiron, D., Lourantou, A., and Chappellaz, J.: Abrupt rise in atmospheric $\mathrm{CO}_{2}$ at the onset of the $\mathrm{B} ø$ lling/Allerød: in-situ ice core data versus true atmospheric signal, Clim. Past, 7, 473-486, https://doi.org/10.5194/cp-7-4732011, 2011.

Köhler, P., Völker, C., Knorr, G., and Bard, E.: High latitude impacts on deglacial $\mathrm{CO}_{2}$ : southern ocean westerly winds and northern hemisphere permafrost thawing, Nova. Act. Lc., 121, 135-140, https://doi.org/10.013/epic.45322.d002, 2015.

Landais, A., Caillon, N., Severinghaus, J., Barnola, J.-M., Goujon, C., Jouzel, J., and Masson-Delmotte, V.: Analyse isotopique de l'air piégé dans la glace pour quantifier les variations de température, C. R. Geosci., 336, 963-970, https://doi.org/10.1016/j.crte.2004.03.013, 2004.

Loulergue, L., Schilt, A., Spahni, R., Masson-Delmotte, V., Blunier, T., Lemieux, B., Barnola, J.-M., Raynaud, D., Stocker, T. F., and Chappellaz, J.: Orbital and millennial-scale features of atmospheric $\mathrm{CH}_{4}$ over the past 800,000 years, Nature, 453, 383-386, https://doi.org/10.1038/nature06950, 2008.

Lüthi, D., Floch, M. L., Bereiter, B., Blunier, T., Barnola, J.-M., Siegenthaler, U., Raynaud, D., Jouzel, J., Fischer, H., Kawamura, K., and Stocker, T. F.: High-resolution carbon dioxide concentration record 650,000-800,000 years before present, Nature, 453, 379-382, https://doi.org/10.1038/nature06949, 2008.

Martinerie, P., Raynaud, D., Etheridge, D. M., Barnola, J.-M., and Mazaudier, D.: Physical and climatic parameters which influence the air content in polar ice, Earth Planet. Sc. Lett., 112, 1-13, https://doi.org/10.1016/0012-821x(92)90002-d, 1992.

Masson-Delmotte, V., M., Schulz, A., Abe-Ouchi, J., Beer, A., Ganopolski, J., González Rouco, E., Jansen, K., Lambeck, J., Luterbacher, T., Naish, T., Osborn, B., Otto-Bliesner, T., Quinn, R., Ramesh, M., Rojas, X. S., and Timmermann, A.: Information from paleoclimate archives, in: Climate change 2013: the physical science basis. Contribution of working group I to the fifth assessment report of the Intergovernmental Panel on Climate Change, edited by: Stocker, T. F., Qin, D., Plattner, G. K., Tignor, M., Allen, S. K., Boschung, J., Nauels, A., Xia, Y., Bex, V., and Midgley, P. M., Cambridge University Press, Cambridge, United Kingdom and New York, NY, USA, 383-464, 2013.

Mitchell, L. E., Buizert, C., Brook, E. J., Breton, D. J., Fegyveresi, J., Baggenstos, D., Orsi, A., Severinghaus, J., Alley, R. B., Al- bert, M., Rhodes, R. H., McConnell, J. R., Sigl, M., Maselli, O., Gregory, S., and Ahn, J.: Observing and modeling the influence of layering on bubble trapping in polar firn, J. Geophys. Res.Atmos., 120, 2558-2574, https://doi.org/10.1002/2014jd022766, 2015.

Morville, J., Kassi, S., Chenevier, M., and Romanini, D.: Fast, lownoise, mode-by-mode, cavity-enhanced absorption spectroscopy by diode-laser self-locking, Appl. Phys. B-Lasers O., 80, 10271038, https://doi.org/10.1007/s00340-005-1828-z, 2005.

Orsi, A. J., Cornuelle, B. D., and Severinghaus, J. P.: Magnitude and temporal evolution of Dansgaard-Oeschger event 8 abrupt temperature change inferred from nitrogen and argon isotopes in GISP2 ice using a new least-squares inversion, Earth Planet. Sc. Lett., 395, 81-90, https://doi.org/10.1016/j.eps1.2014.03.030, 2014.

Petit, J. R., Jouzel, J., Raynaud, D., Barkov, N. I., Barnola, J.-M., Basile, I., Bender, M. L., Chappellaz, J., Davis, M., Delaygue, G., Delmotte, M., Kotlyakov, V. M., Legrand, M., Lipenkov, V. Y., Lorius, C., Pépin, L., Ritz, C., Saltzman, E., and Stievenard, M.: Climate and atmospheric history of the past 420,000 years from the Vostok ice core, Antarctica, Nature, 399, 429436, https://doi.org/10.1038/20859, 1999.

Rhodes, R. H., Faïn, X., Stowasser, C., Blunier, T., Chappellaz, J., McConnell, J. R., Romanini, D., Mitchell, L. E., and Brook, E. J.: Continuous methane measurements from a late Holocene Greenland ice core: atmospheric and in-situ signals, Earth Planet. Sc. Lett., 368, 9-19, https://doi.org/10.1016/j.eps1.2013.02.034, 2013.

Rhodes, R. H., Brook, E. J., Chiang, J. C. H., Blunier, T., Maselli, O. J., McConnell, J. R., Romanini, D., and Severinghaus, J. P.: Enhanced tropical methane production in response to iceberg discharge in the North Atlantic, Science, 348, 1016-1019, https://doi.org/10.1126/science.1262005, 2015.

Rhodes, R. H., Faïn, X., Brook, E. J., McConnell, J. R., Maselli, O. J., Sigl, M., Edwards, J., Buizert, C., Blunier, T., Chappellaz, J., and Freitag, J.: Local artifacts in ice core methane records caused by layered bubble trapping and in situ production: a multi-site investigation, Clim. Past, 12, 1061-1077, https://doi.org/10.5194/cp-12-1061-2016, 2016.

Romanini, D., Chenevier, M., Kassi, S., Schmidt, M., Valant, C., Ramonet, M., Lopez, J., and Jost, H.-J.: Optical-feedback cavityenhanced absorption: a compact spectrometer for real-time measurement of atmospheric methane, Appl. Phys. B-Lasers O., 83, 659-667, https://doi.org/10.1007/s00340-006-2177-2, 2006.

Rommelaere, V., Arnaud, L., and Barnola, J.-M.: Reconstructing recent atmospheric trace gas concentrations from polar firn and bubbly ice data by inverse methods, J. Geophys. Res.-Atmos., 102, 30069-30083, https://doi.org/10.1029/97jd02653, 1997.

Rousseeuw, P. J. and Hubert, M.: Robust statistics for outlier detection, Wires Data Min. Knowl., 1, 73-79, https://doi.org/10.1002/widm.2, 2011.

Schwander, J.: The transformation of snow to ice and the occlusion of gases, in: The environmental record in glaciers and ice sheets, edited by: Oeschger, H. and Langway, C. C. J., John Wiley, New York, 53-67, 1989.

Schwander, J., Barnola, J.-M., Andrié, C., Leuenberger, M., Ludin, A., Raynaud, D., and Stauffer, B.: The age of the air in the firn and the ice at Summit, Greenland, J. Geophys. Res.-Atmos., 98, 2831-2838, https://doi.org/10.1029/92jd02383, 1993. 
Spahni, R., Schwander, J., Flückiger, J., Stauffer, B., Chappellaz, J., and Raynaud, D.: The attenuation of fast atmospheric $\mathrm{CH}_{4}$ variations recorded in polar ice cores, Geophys. Res. Lett., 30, 25-1-25-4, https://doi.org/10.1029/2003g1017093, 2003.

Stauffer, B., Fischer, G., Neftel, A., and Oeschger, H.: Increase of atmospheric methane recorded in antarctic ice core, Science, 229, 1386-1388, https://doi.org/10.1126/science.229.4720.1386, 1985.

Stauffer, B., Schwander, J., and Oeschger, H.: Enclosure of air during metamorphosis of dry firn to ice, Ann. Glaciol., 6, 108-112, https://doi.org/10.3189/1985AoG6-1-108-112, 1985.

Storn, R. and Price, K.: Differential evolution - A simple and efficient heuristic for global optimization over continuous spaces, J. Global. Optim., 11, 341-359, https://doi.org/10.1023/a:1008202821328, 1997.

Stowasser, C., Buizert, C., Gkinis, V., Chappellaz, J., Schüpbach, S., Bigler, M., Faïn, X., Sperlich, P., Baumgartner, M., Schilt, A., and Blunier, T.: Continuous measurements of methane mixing ratios from ice cores, Atmos. Meas. Tech., 5, 999-1013, https://doi.org/10.5194/amt-5-999-2012, 2012.

Trudinger, C. M., Enting, I. G., Etheridge, D. M., Francey, R. J., Levchenko, V. A., Steele, L. P., Raynaud, D., and Arnaud, L.: Modeling air movement and bubble trapping in firn, J. Geophys. Res.-Atmos., 102, 6747-6763, https://doi.org/10.1029/96jd03382, 1997.
Vasiliev, N., Talalay, P., Bobin, N., Chistyakov, V., Zubkov, V., Krasilev, A., Dmitriev, A., Yankilevich, S., and Lipenkov, V. Y.: Deep drilling at Vostok station, Antarctica: history and recent events, Ann. Glaciol., 47, 10-23, https://doi.org/10.3189/172756407786857776, 2007.

Veres, D., Bazin, L., Landais, A., Toyé Mahamadou Kele, H., Lemieux-Dudon, B., Parrenin, F., Martinerie, P., Blayo, E., Blunier, T., Capron, E., Chappellaz, J., Rasmussen, S. O., Severi, M., Svensson, A., Vinther, B., and Wolff, E. W.: The Antarctic ice core chronology (AICC2012): an optimized multi-parameter and multi-site dating approach for the last 120 thousand years, Clim. Past, 9, 1733-1748, https://doi.org/10.5194/cp-9-17332013, 2013.

Witrant, E., Martinerie, P., Hogan, C., Laube, J. C., Kawamura, K., Capron, E., Montzka, S. A., Dlugokencky, E. J., Etheridge, D., Blunier, T., and Sturges, W. T.: A new multi-gas constrained model of trace gas non-homogeneous transport in firn: evaluation and behaviour at eleven polar sites, Atmos. Chem. Phys., 12, 11465-11483, https://doi.org/10.5194/acp-12-114652012, 2012. 